\section{$\triangle 349$}

VIRUSES IN THE RESPIRATORY TRACT OF SIDS VICTIMS: VIROLOGICAL AND CLINICAL COMPARISONS.

Igor A.Kelmanson. Department of Paediatrics No.3, St.Petersburg Paediatric Medical Institute, Litovskaya 2, St.Petersburg, 194 100, Russia.

Much interest has been raised on the association between the cases of sudden infant death syndrome (SIDS) and positive virological findings in the victims. A retrospective study was undertaken which encompassed all 197 infants who died of SIDS and 81 non-SIDS out-patient babies who died suddenly of definite respiratory infections in St.Petersburg in 1983-89. Respiratory agents were revealed in 119 of 197 SIDS babies $(60.4 \%)$ by means of immunofluorescent (IF) analysis and in all the non-SIDS cases. No difference was found for age- and sex distribution between IF-positive, IFnegative SIDS babies and non-SIDS infants. The frequency with which particular respiratory agents were revealed in IF-positive SIDS cases and in non-SIDS infants did not significantly differ: the leading were respiratory syncytial virus (RSV) and influenza virus. Specific antibodies against these two viruses were more often revealed in the infants who died of definite respiratory infections. No difference was found for the frequency with which particular clinical signs and symptoms prior to death were found in IF-positive and IF-negative SIDS babies. Warning clinical findings were more frequent in non-SIDS cases.

\section{2}

DECREASED PLASMA BETA ENDORPHINS LEVELS (BE) AFTER TREATMENT OF GASTRO OESOPHAGEAL REFLUX (GER) IN BABIES ADMITTED FOR ACUTE LIFE THREATENING

EPISODES (ALTE) : C. BAYAERT, P. MONIN , B DOUSSET, F. MARCHAL, Service de Pédiatrie 1, Laboratoire d'explorations fonctionnelles pédiatriques et Laboratoire de Biochimic, CHU de NANCY-BRABOIS 54511 NANCY.

GER frequent during the first months of life is considered as a risk factor for ALTE or SIDS. In a previous work we have shown the presence of an increased plasma BE levels in babies with ALTE and GER. In 14 patients admitted for ALTE., 10 had marked GER. BE levels were determined at admission in all subjects and after tratment in 9 . Ventilation and occlusion pressure at $100 \mathrm{~ms}(\mathrm{PO}$.1) were measured with treatment in a face mask, pneumotachograph and pressure transducer during natural sleep at the same time. On admission BE was increased significantly in babies with GER $(n=10)$ when compared to babies without GER (repectively $58.6 \pm 18.9$ vs $28 \pm 15.8 \mathrm{pg} / \mathrm{ml}$, p $<0.025)$. In the 9 cases studied (wice, 6 had GER at admission. In 4 of them GER was resolved afier treatment and BE levels dropped from $53 \pm 71017 \pm 2 \mathrm{pg} / \mathrm{ml}$. In the 2 cases without GER improvement. BE levels remained stable ( 68 vs 62 and 67 vs 46 $\mathrm{pg} / \mathrm{ml}$ ). Of the 3 cases with no significant GER at the first study one was highly agitated and another showed a long episode of GER; in these 2 patients BE levels were increased at the 2nd determination (14 to 50 ) and 18 to $120 \mathrm{pg} / \mathrm{ml}$ ).

None of the ventilatory parameters (VE, RR, VT, Ti, Te or P 0.1) corralated with beta endorphin levels. $P 0.1$ was within the normal range $\left(4.58 \pm 1.3 \mathrm{~cm} \mathrm{H}_{2} \mathrm{O}\right)$. In 2 cases with $\mathrm{P}() .1$ below $3 \mathrm{cmH} 2 \mathrm{O}$ ( 19 and $2.9 \mathrm{~cm} \mathrm{H} 2 \mathrm{O}$, BE levels were elevated., respectively 58 and $64 \mathrm{pg} / \mathrm{ml}$. High levels of $\mathrm{BE}$ associated to GER are reduced by respectively 58 and $64 \mathrm{pg} / \mathrm{ml}$. High levels of $\mathrm{BE}$ associated $\mathrm{to}$ GER are reduced by
GER treatment. However, an influence of increased levels of $\mathrm{BE}$ on ventilation could not be demonstrated. (Reseau INSERM 9012 )

\section{$\Delta 350$}

THERMOREGULATORY FLUCTUATIONS IN SKIN BLOOD FLOH AND HEART RATE VARIABILITY IN INFANTS.

Kristin Lossius and Morten Eriksen (spn. by Asbjern Langslet)

Department of Physiology, University of Oslo, and Department of Paediatrics, Ulleval Hospital, Oslo, Norway.

Dysfunction in the control of heart rate (HR) and/or body temperature may predispose infants to SIDS, but the connection between thermoregulation and HR control in infants is unknown.

thermoregulation and HR control in infants is unknown. Spontaneous flucetuations in th and Skin blood How (SBF), measured with laser Joppler, were investigated in newborn infants, and the investigation was repeated at three months. SBF was measured in the palms, where there are numerous arteriovenous anastomoses.

Both newborn and three month old infants showed characteristic fluctuations in SBF, which were closely related to variations in HR. Sudden vasoconstrictions were accompanied by a diphasic HR response, consisting of an initial acceleration, probably caused by coactivation of cardiac and cutaneous nerve fibres, followed by a deceleration, probably caused by baroreceptor artivity.

In an earlier study on adult subjects, we have demonstrated a similax diphasic $H R$ response. In adults, the secondazy, baroreceptormediated bradycardia was transient, lasting only a few heart beats. In infants, however, the HR deceleration lasted longer, and closely In lnfants, however, the hr deceleration lasted id followed the time course of the vasoconstriction. The different kR response in infants and adults may reflect maturation of the baroreceptor reflex. The ability of Eeripheral vasodilatation may be less well developed in infants, which makes HR more important in the requlation of blood pressure.
351

\section{CHILDRENS' LYMPHOCYTES HAVE A SHORTER LIFESPAN THAN} ADULTS'- RELEVENCE TO HIV BIOLOGY.

Colin A. Michie. Department of Paediatrics and Neonatal Medicine, Royal Postgraduate Medical School, LONDON.

The period between divisions of a cell may be estimated using radiationinduced chromosome damage as a marker. Chromosome exchanges producing dicentric chromosomes prevent chromatid separation at mitosis leading to cell death. The frequency of cells with this type of damage over time after radiation gives an estimate of cell lifespan. Using statistics developed to estimate lymphocyte lifespans in adults following radiotherapy, published data from individuals exposed to radiation in Hiroshima (numbers of cases, $n=60)$, in the Ukraine after Chernobyl $(n=25)$ and Goiania in Brazil $(n=14)$ were analysed. The table illustrates lymphocyte lifespan results in years. Children would appear to have lymphocytes with shorter intermitotic limes than adults. This observation is important with respect to the pattern of HIV infection in children for two reasons. Firstly the virus will be limited to infecting cells at a lower rate than in an adult, secondly viral cytotoxicity will be less damaging to the paediatric immune system in early stages of the disease.

$\begin{array}{llll}\text { Median age, yr. }(n): & 9(30) & 30(32) & 55(37) \\ \text { Average time to cell death, yr. (ISE): } & 12(6) & 16(5) & 20(8)\end{array}$

\section{3}

HEART RATE VARIABILITY AND SUDDEN INFANT DEATH SYNDROME

Francesco Perticone, Raffaele Maio, Carmela cosco, Fabiola Pugliese, Cosima Cloro, Domenico A. Borelli, Pier L. Mattioli. Dpt of Medicina Sperimentale e Clinica, Medical School at Catanzaro, University of Reggio Calabria, Italy

We studied 465 newborns enrolled in a previous prospective electrocardiographic study to evaluate the predictive value of QT interval for SIDS. We analyzed the ECGs recorded with babies alert on the 4th day of life and after $2,4,6$ and 12 months. For each $E O G$, the HRV was calculated using the first standard deviation of $\mathrm{RR}$ intervals (ms) measured for 2 mimutes. Besides, the HRV values were correlated with QTc values in order to asses a possible relationship between the 2 variables. Data are reported in table:

\begin{tabular}{|lcccccc|}
\hline & & 4 days & 2 months & 4 months 6 months & 1 year \\
& $n=$ & 465 & 465 & 174 & 151 & 61 \\
\hline QTC & & $401 \pm 25$ & $416 \pm 19$ & $408 \pm 19$ & $400 \pm 18$ & $397 \pm 24$ \\
HRV (ms) & & $22 \pm 14$ & $16 \pm 8$ & $20 \pm 12$ & $20 \pm 11$ & $23 \pm 16$ \\
RR (ms) & & $452 \pm 75$ & $414 \pm 39$ & $451 \pm 47$ & $457 \pm 45$ & $466 \pm 64$ \\
& $r$ & -.50 & -.18 & -.09 & -.20 & -.18 \\
QTC/HRV & $\mathrm{p}$ & $<.000001$ & $<.0001$ & NS & NS & NS \\
& & & & & &
\end{tabular}

our data seems to confinm a delayed maturation or impaired fuctioning of the autonomic nervous system in the first months of life, reflecting a direct correlation with QT prolongation.

\section{4}

THE CRIB DEATH: QT INTERVAL AND HR DURING THE FIRST YEAR OF IIFE Crisara, Olga Cuccurullo, Roberto Ceravolo, Pier L. Mattioli. Dpt of Medicina Sperimentale e Clinica, Medical School at Catanzaro, University of Reggio Calabria, Italy

A prospective electrocardiographic study was performed in 2,572 newborns, 1,326 males and 1,246 females, to evaluate the predictive value of $\mathrm{QT}$ interval for sudden infant death syndrome (SIDS). Electrocardiograms, with babies asleep, were recorded at the ages of 4 days, 2, 4, 6 months, and 1 year. The QTC (mean \pm SD) was $391+23$ at 4 days, $412+16$ at 2 months $(n=1,768) \quad(p<.0001)$. $404 \pm 17$ at 4 months $(n=1,368), 401 \pm 16$ at 6 months $(n=1,225)$, and $397 \pm 16$ at 1 year $(n=915)$. OTC, calculated in males and females, resulted significantly longer (393 vs 391) (p<.01) at 4 days. QTc values longer than the mean plus 3 SD were considered prolonged. Heart rate values were 13516 at 4 days, $145+15$ at 2 months $(p<.0001), 135 \pm 11$ at 4 months, $133 \pm 11$ at 6 months, and $129 \pm 9$ at 1 year. In 71 babies $(2.8 \%)$ the QTC was prolonged and $4(0.16 \%)$ of these died suddenly: the first at 3 months ( $Q T C=470, H R=147)$; the second after 7 weeks ( $R T C=514, H R=115)$; the third at 3 months ( $Q T C=464, H R=140$ at 4 days; the fourth at 2 months (QTO=401; $\mathrm{HR}=149$ ). In conclusion, our data provide further information on the understanding of SIDS mechanisms. Francesco Perticone, Fabiola Pugliese, Raffaele costa, Domenico 